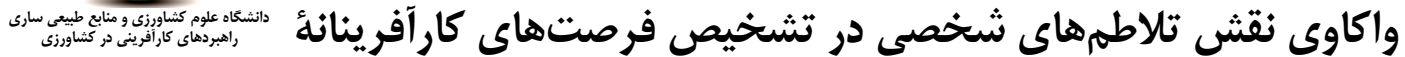

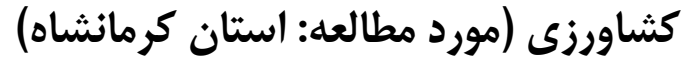

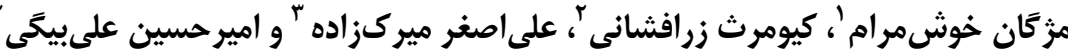

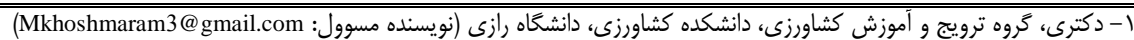

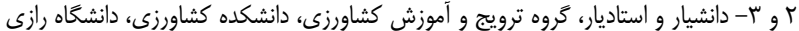

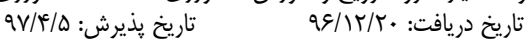

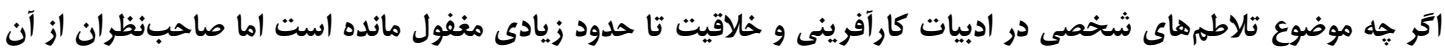

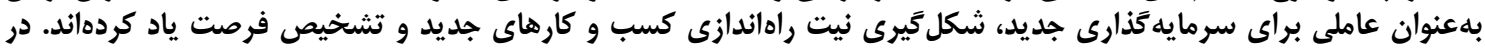

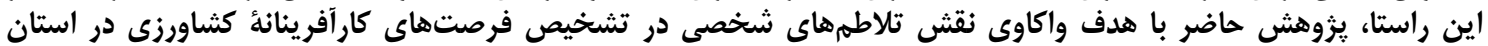

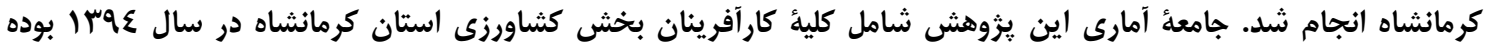

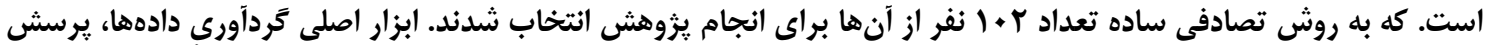

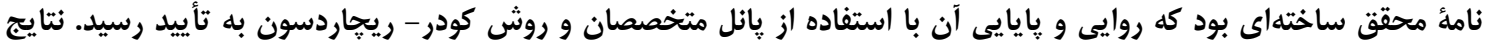

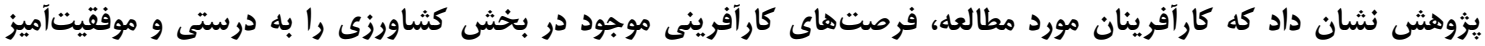

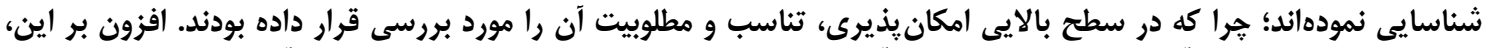

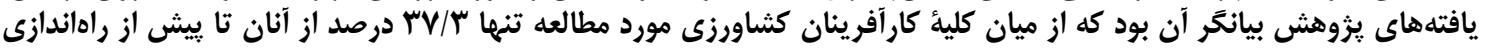

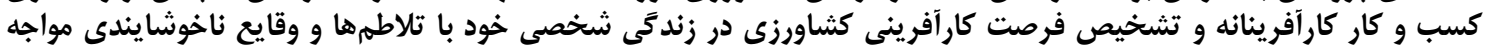

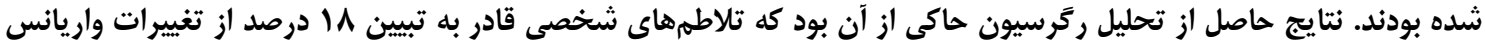

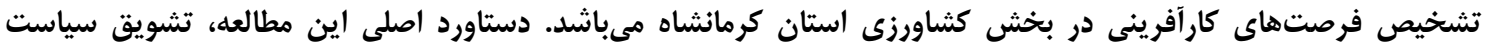

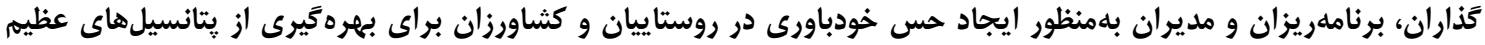
بخش كثاورزى مىباشد.

وازههاى كليدى: امكان يذيرى فرصت، مطلوبيت فرصت، كارآفرينى كثاورزى، اقدامات كارآفرينانه

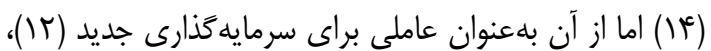

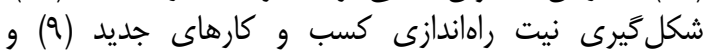

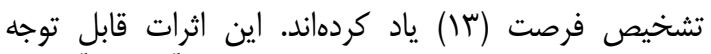

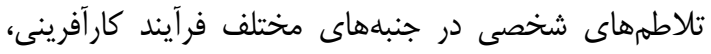

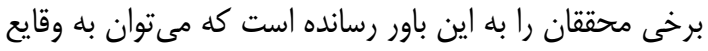

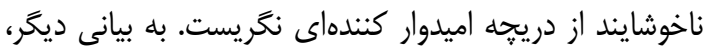

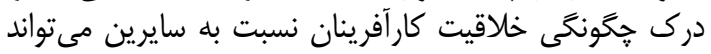

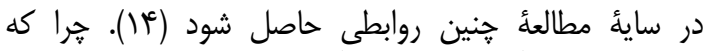

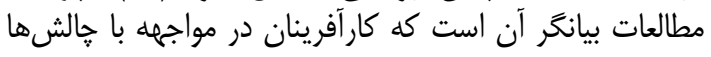

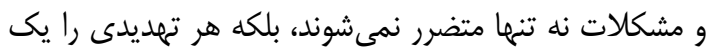

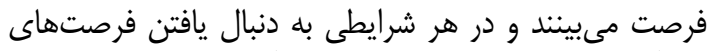

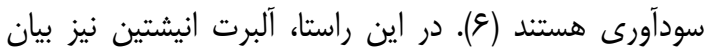

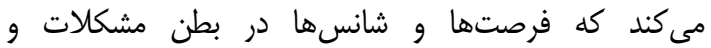

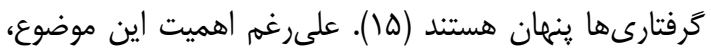

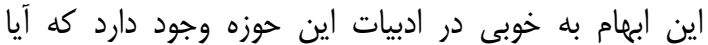

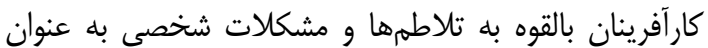

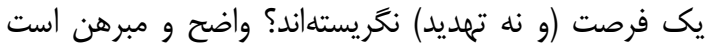

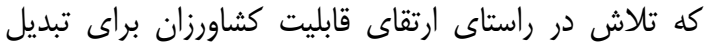

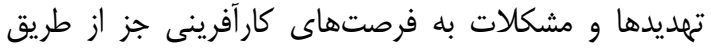

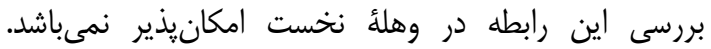

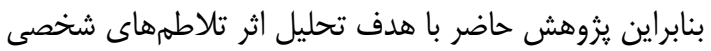

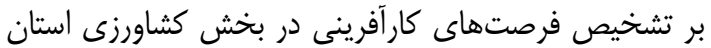

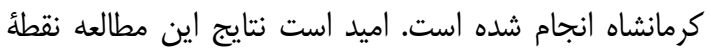

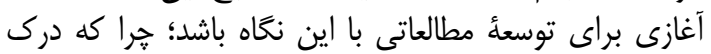

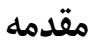

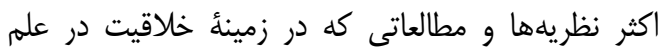

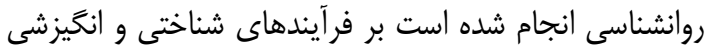

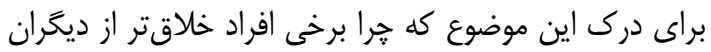

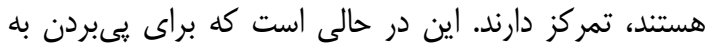

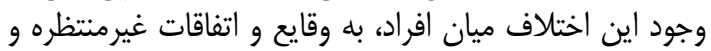

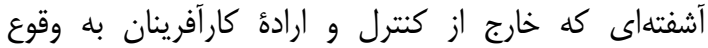

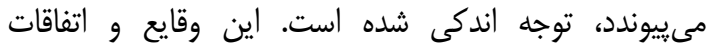

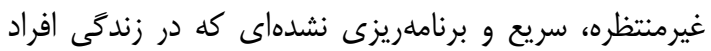

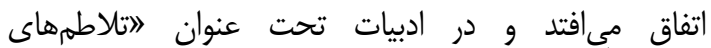

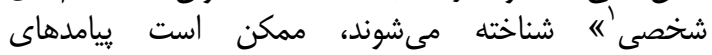

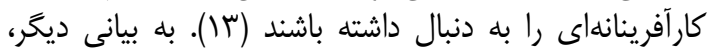

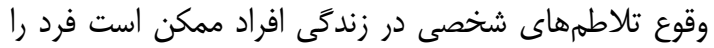

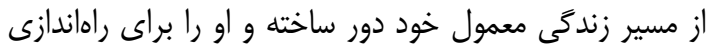

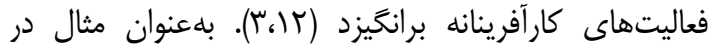

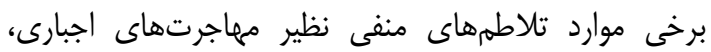

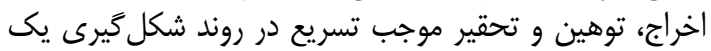

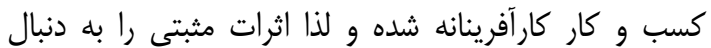

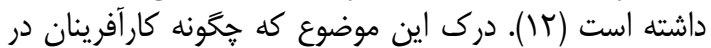

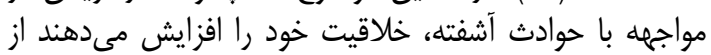

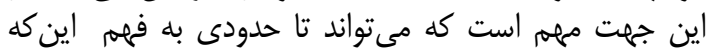

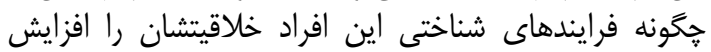

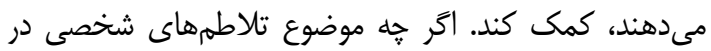
ادبيات كارآفرينى و خلاقيت كنا جا حدود زيادى منفول مانده است 
if

تشخيص فرصتهاى كارآفرينى بود. براى سنجش تلاطم

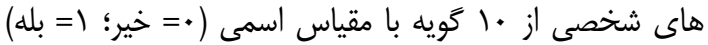

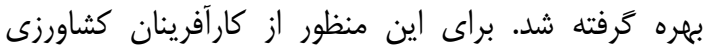

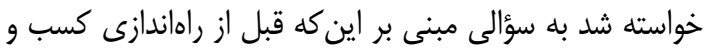

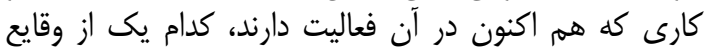

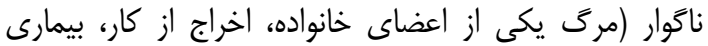

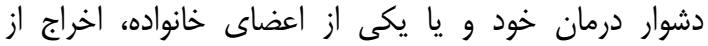

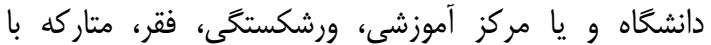

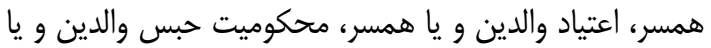

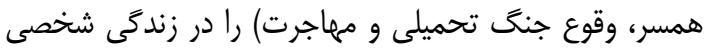

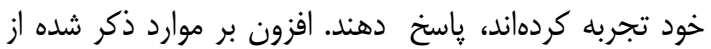

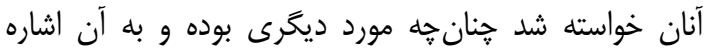

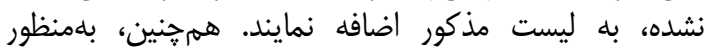

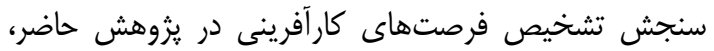

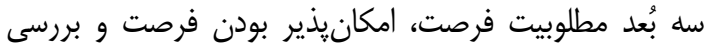

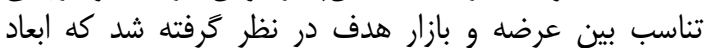

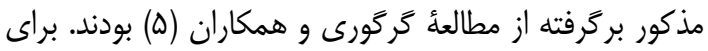

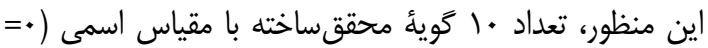

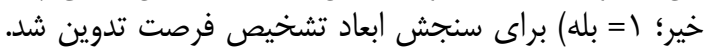

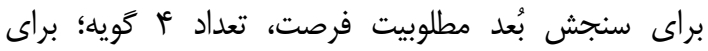

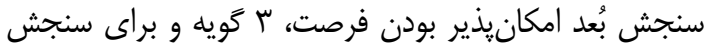

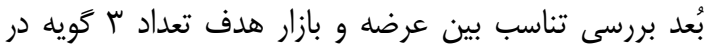
نظر كَرفته شد (جدول ()).

عوامل مؤثر بر شناسايى فرصت، اطلاعات مفيدى را براى

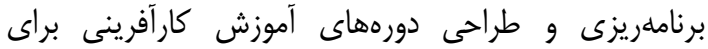

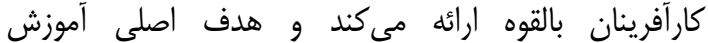

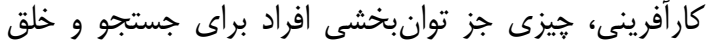

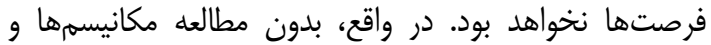

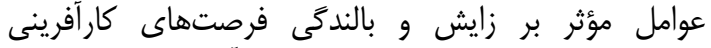
نمىتوان به فهم دقيقى از كليت كارآفرينى دست يأن يافت

\section{مواد و روشها}

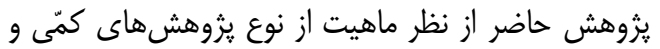

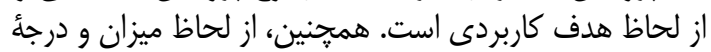

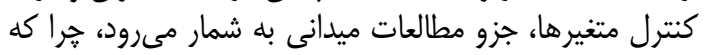

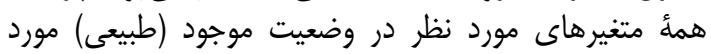

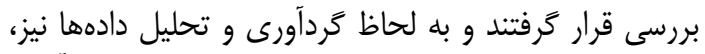

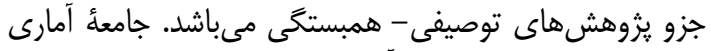

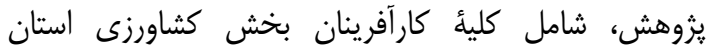

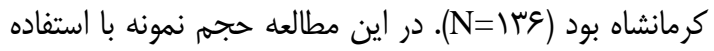

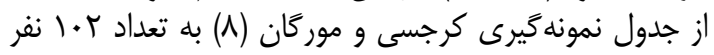

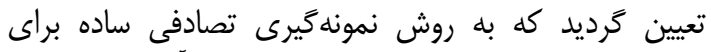

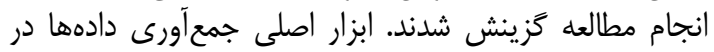

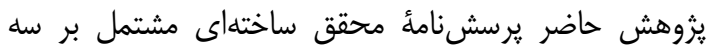

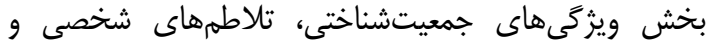

جدول ا- كويههاى سنجش تشخيص فرصتهاى كار آفرينى Table 1. Items for assessment of entrepreneurial opportunity recognition لطفا موارد زير را به دقت مطالعه نموده و بكوييد ييش از راهاندازى كسب و كار كارأفرينانهاى كه هماكنون در آن فعاليت داريد كدام يك از سوالات زير را از خود يرسيديد و

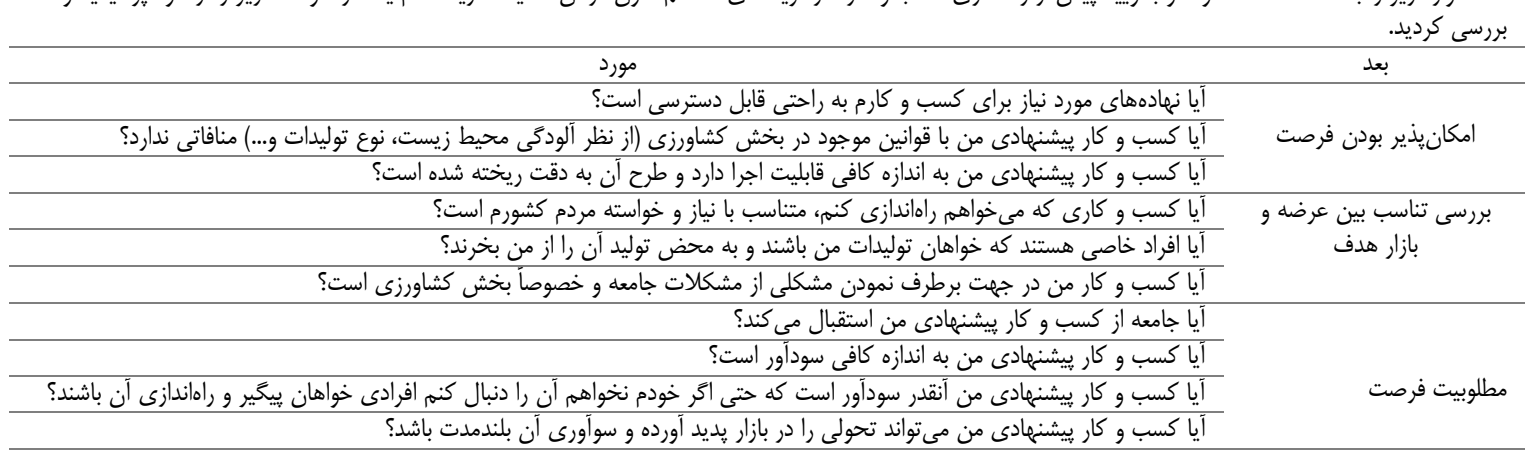

يرسشنامه اعمال شد و به تأييد نهايى متخصصان مذكور

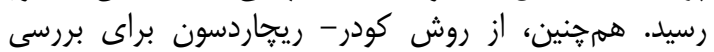

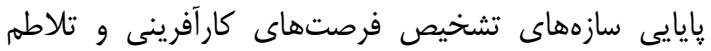

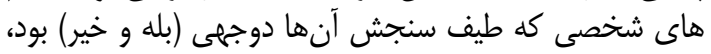

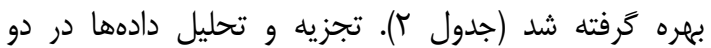

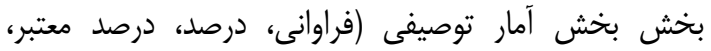

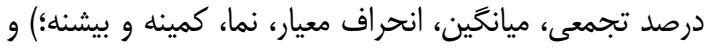

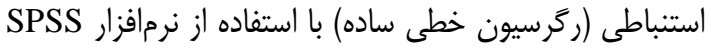

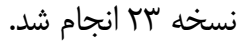

در يزوهش حاضر، كارآفرينانى موفق به تشخيص فرصت

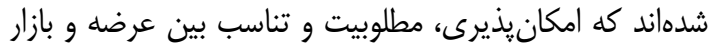

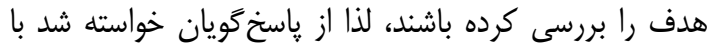

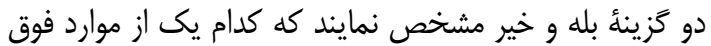

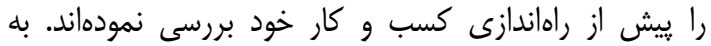

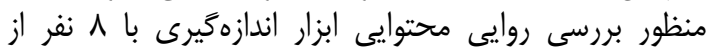

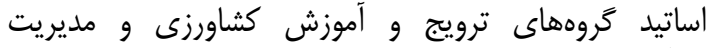

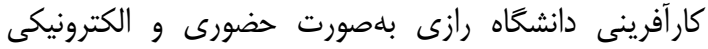

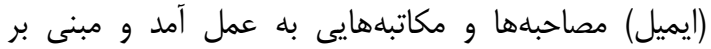
نظرات و ديدگاههاى آنان تغييرات و اصلاحاتى در سؤالات 
Table 2. The reliability of instrument

جدول r- بررسى ڤايايى ابزار يزوهش

\begin{tabular}{|c|c|c|c|}
\hline 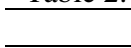 & ضريب كودر - ريجاردسون (KR) & تعداد كويه & \\
\hline & $\cdot / \mathrm{VI}$ & $r$ & - امكان يذيرى فرصت \\
\hline & $\cdot / V^{e}$ & i & - مطلوبيت فرصت \\
\hline & $\cdot / V^{2}$ & r & - تناسب بين عرضه و بازار هدف \\
\hline & $\cdot / \mathrm{VA}$ & 1. & - تلاطم شخصى \\
\hline
\end{tabular}

نوع فعاليت كارآفرينانهاى كه داشتند، شركت نموده بودند. در

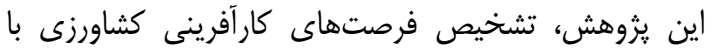

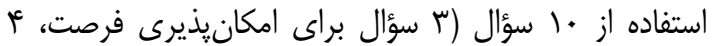

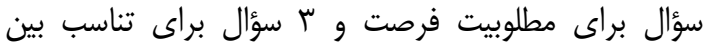

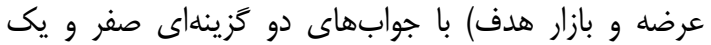

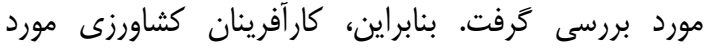

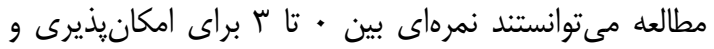

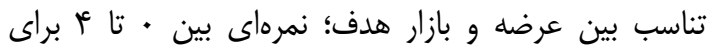

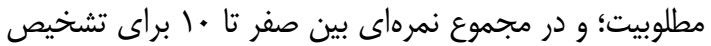
فرصتهاى كارآفرينى كشاورزى كسب مجنى كنند. بر اين اساس،

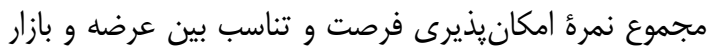

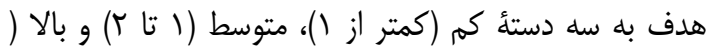

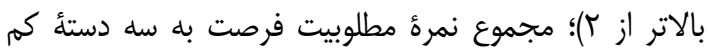

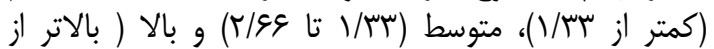

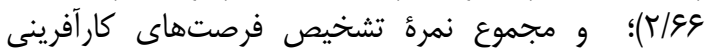

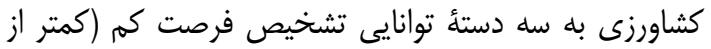

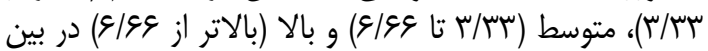

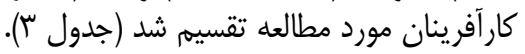

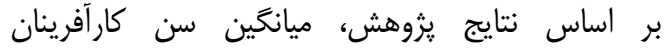

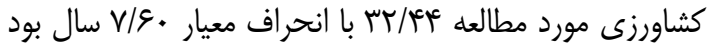

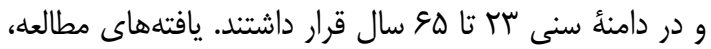

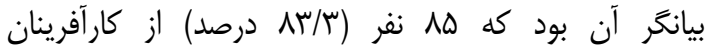

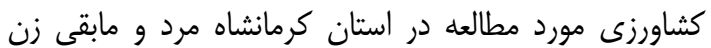

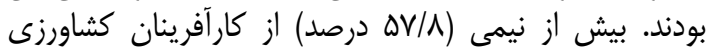

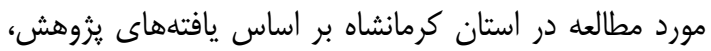

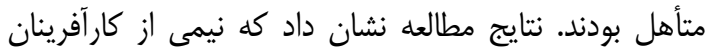

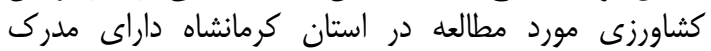

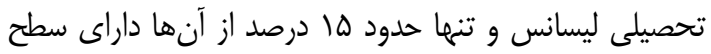

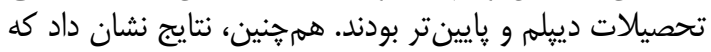

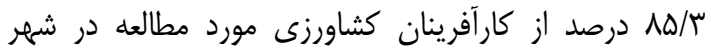

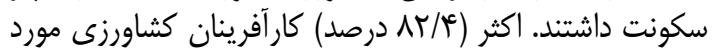

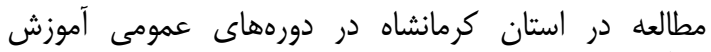

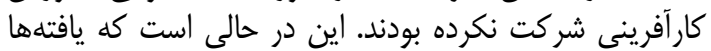

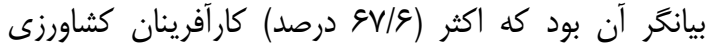

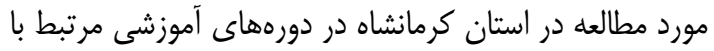

جدول ب- توزيع فراوانى ياسخگَويان بر اساس ابعاد تشخيص فرصتهاى كارآفرينى Table 3. Frequency distribution of respondents based on the dimensions of entrepreneurial opportunity recognition

\begin{tabular}{|c|c|c|c|c|c|c|c|c|}
\hline \multirow[b]{2}{*}{ 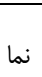 } & \multirow[b]{2}{*}{ ميانخين } & \multicolumn{2}{|c|}{ بالا } & \multicolumn{2}{|c|}{ متوسط } & \multicolumn{2}{|c|}{ كم } & \multirow[b]{2}{*}{ ابعاد/ سطوح } \\
\hline & & درصد & فراوانى & درصد & فراوانى & درصد & فراوانى & \\
\hline بالا & $r / \cdot 9$ & $4+/ 1$ & id & $T / 9$ & tr & $m y / s$ & ra & امكانيذيرى فرصت \\
\hline بالا & $r / V T$ & $\Lambda \cdot / 4$ & AT & $1 F / V$ & 10 & $r / q$ & $\Delta$ & تناسب بين عرضه و بازار هدف \\
\hline بالا & 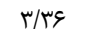 & $\Lambda \mu / r$ & $\Lambda \Delta$ & $r / q$ & $\Delta$ & $11 / 1$ & it & مطلوبيت فرصت \\
\hline بالا & $\Lambda / \Lambda$ & $\Lambda \mathrm{V} / \mathrm{\sim}$ & 19 & $\Lambda / \Lambda$ & $q$ & $r / q$ & f & تشخيص فرصت كارآفرينى \\
\hline
\end{tabular}

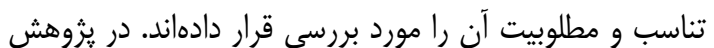

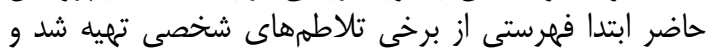

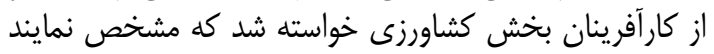

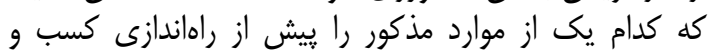

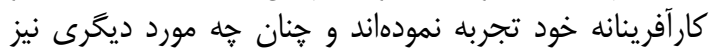

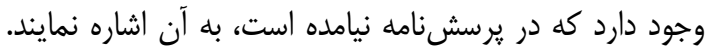

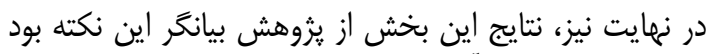

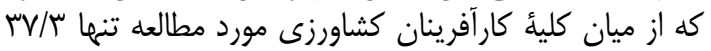

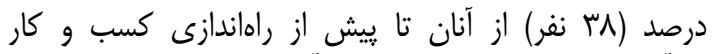

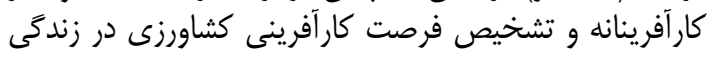

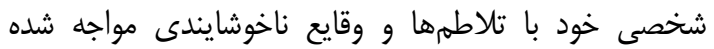

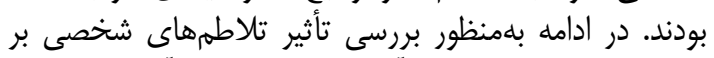

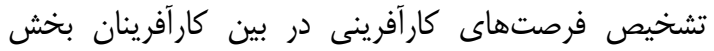

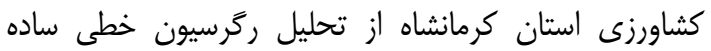

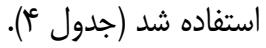

براساس نتايج ارائه شده در جدول (T) مشاهده مى شود كه

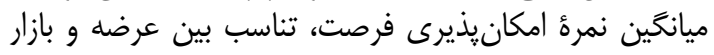

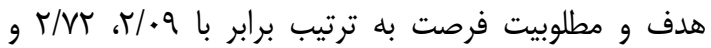

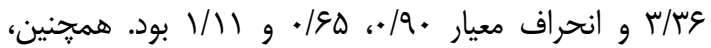

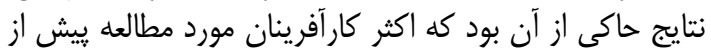

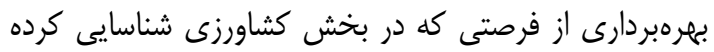

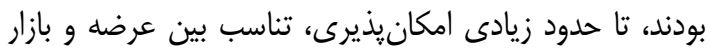

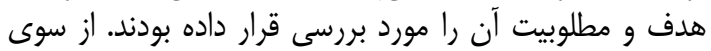

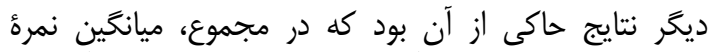

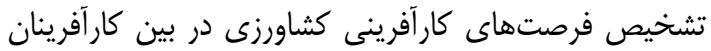

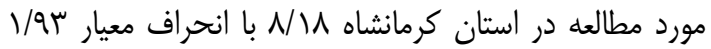

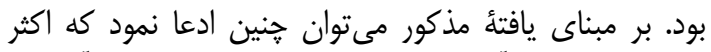
(1V/T)

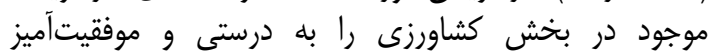

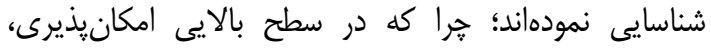


Table 4. The effect of personal turbulence on entrepreneurial opportunity recognition

جدول ז- تأثير تلاطمهاى شخصى بر تشخيص فرصتهاى كارآفرينى سطح معنىارى

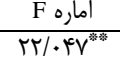
ضريب تعيين تعديل شده ./11 ضريب همبستى خندكانه

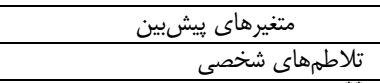

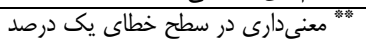

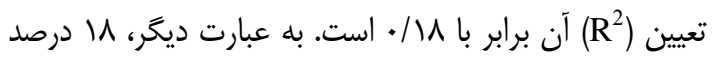

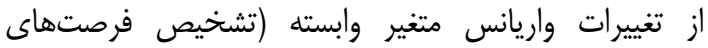

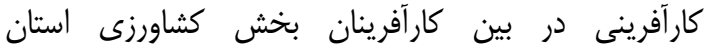
كرمانشاه) توسط تلاطمهاى شخصى تبين دين مى شود.
نتايج ارائه شده در جدول (أ) نشان مى شیدهد كه

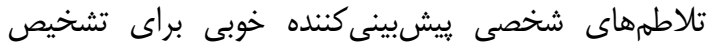

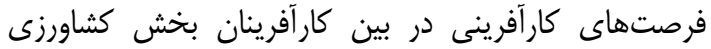

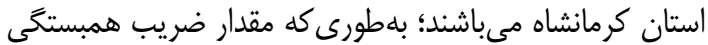

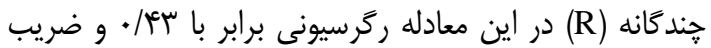

جدول ه- مقادير و سطح معنىدارى تأثير تلاطمهاى شخصى بر تشخيص فرصتهاى كارآفرينى Table 5. Values and p-values of the effect of Personal Turbulence on the entrepreneurial opportunity recognition

\begin{tabular}{|c|c|c|c|c|}
\hline سطح معنى دارى & أزمون t & ضريب استاندارد شده & ضريب ركر سيون غيراستاندارد & متغير \\
\hline.$\cdot \cdot r$ & $r / / \varphi^{*}$ & - & T/Tr & ضريب ثابت \\
\hline.$\ldots$ & $\kappa / V \cdot{ }^{* * *}$ & . ATA & $1 / \mu$. & تلاطمهاى شخصى (X1) \\
\hline
\end{tabular}

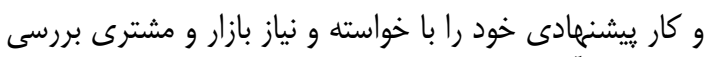

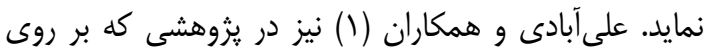

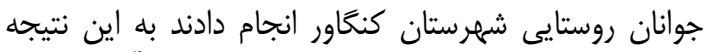

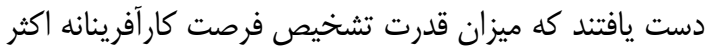

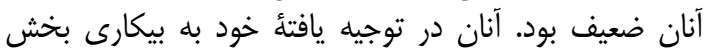

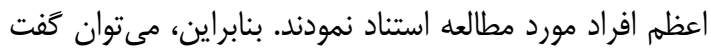

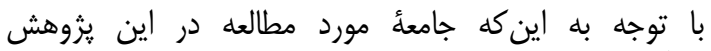

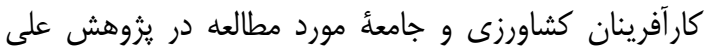

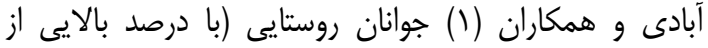

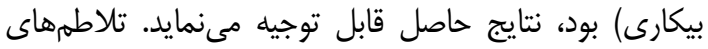

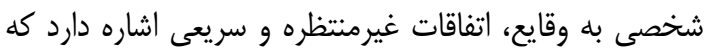

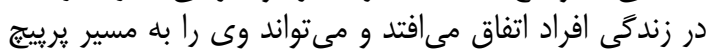

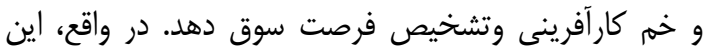

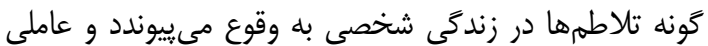

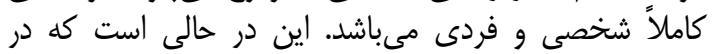

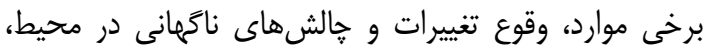

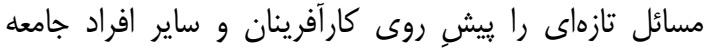

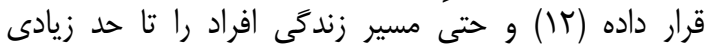

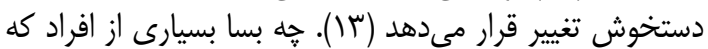

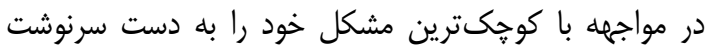

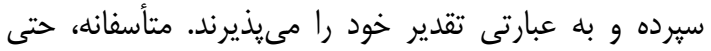

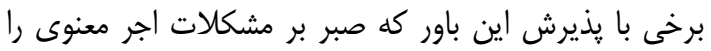

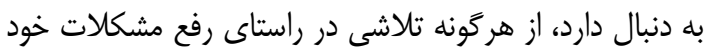

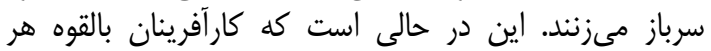

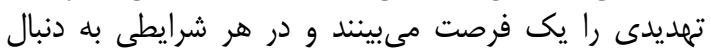

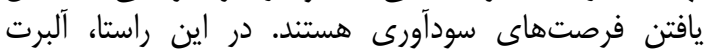

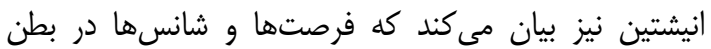

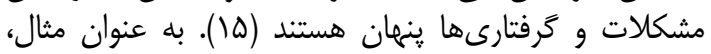

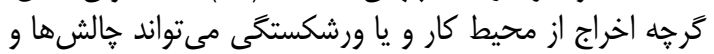

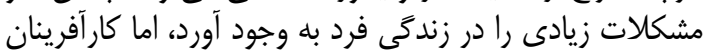

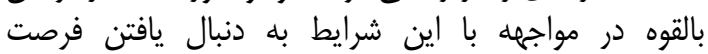

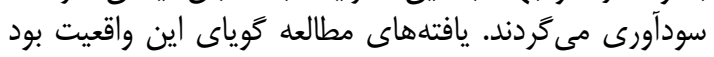

با توجه به توضيحات بالا و نتايج ارائه شده در جدول ه؛

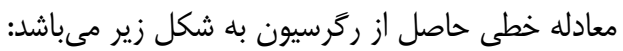
$\mathrm{Y}=3.32+1.30 \mathrm{X} 1$

در معادله فوق، Y متغير وابسته يثوهش يعنى تشخيص

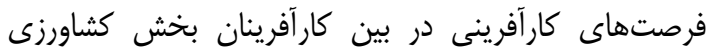

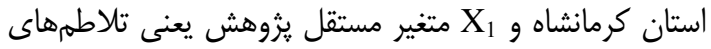
شخصى است.

يافتهاى يثروهش نشان داد كه اكثر كارآفرينان مورد

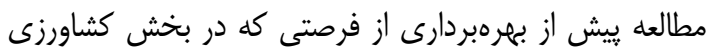

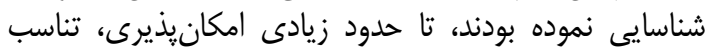

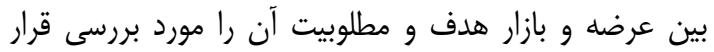

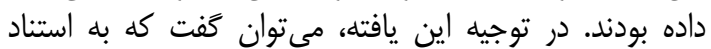

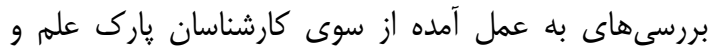

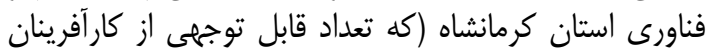

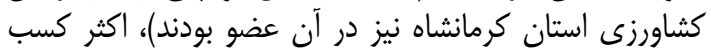

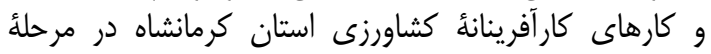

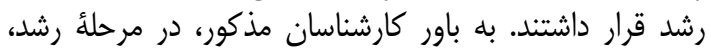

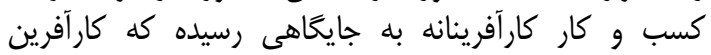

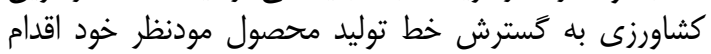

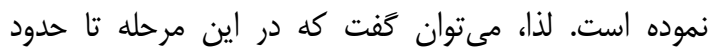

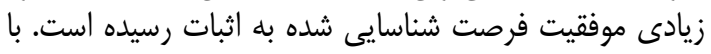

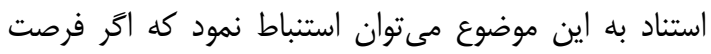

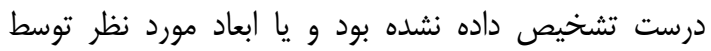

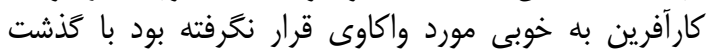

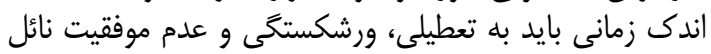

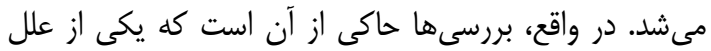

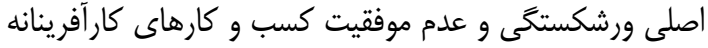

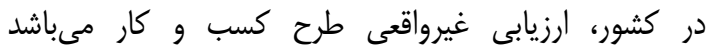

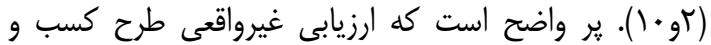

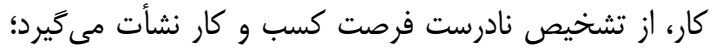

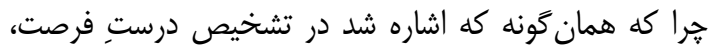

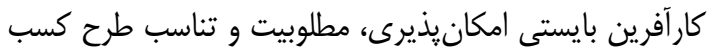




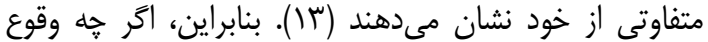

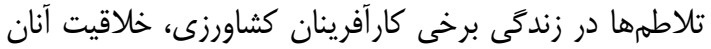

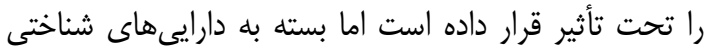

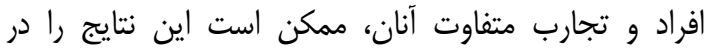

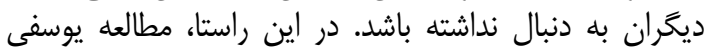

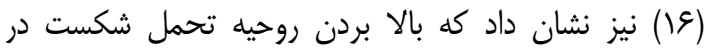

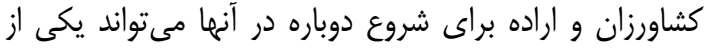

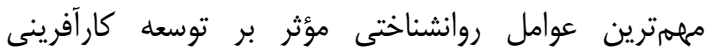

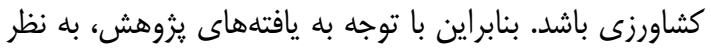

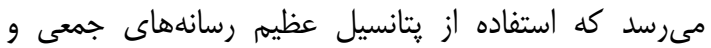

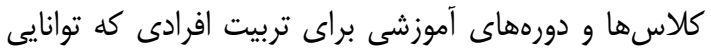

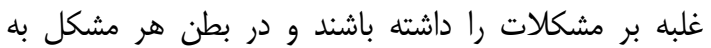

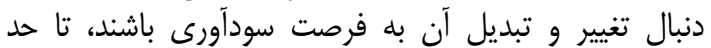

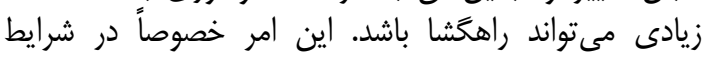

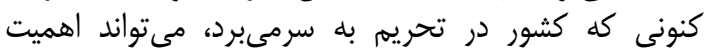

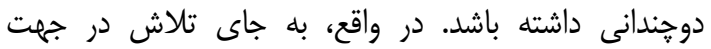

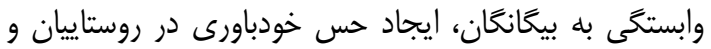

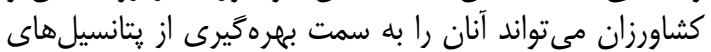
عظيم بخش كشاورزى ترغيب نمايد.

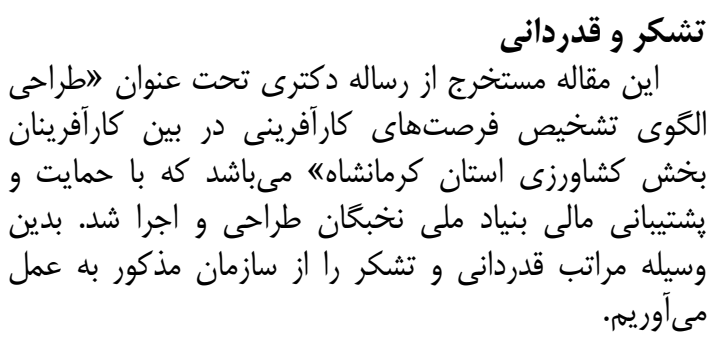

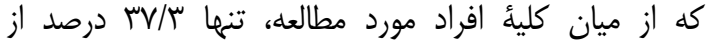

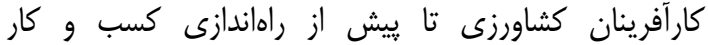

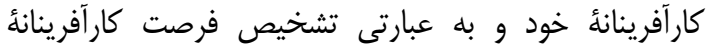

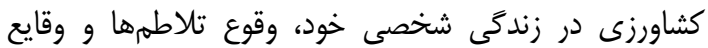

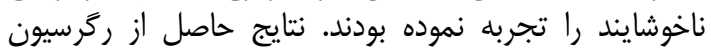

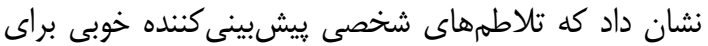

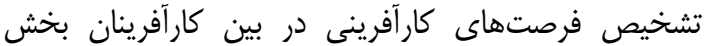

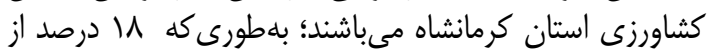

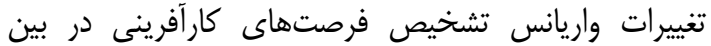

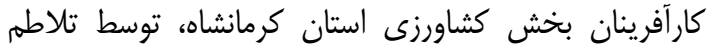

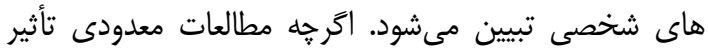

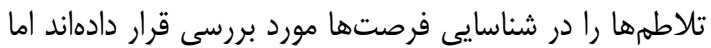

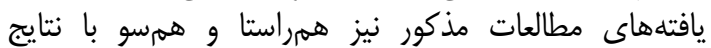

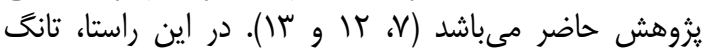

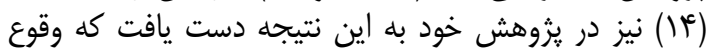

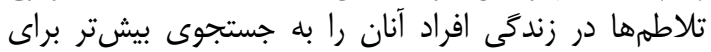

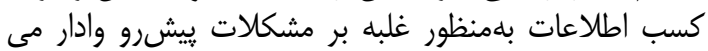

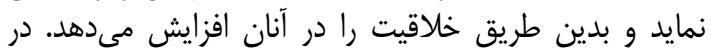

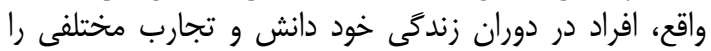

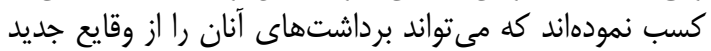

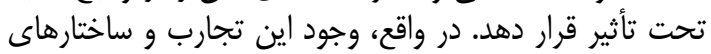

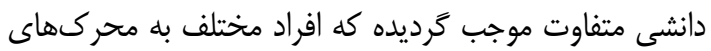

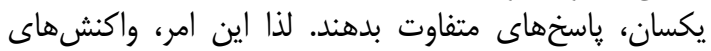

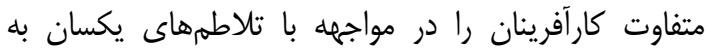

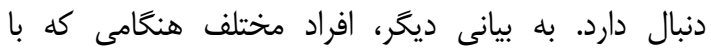

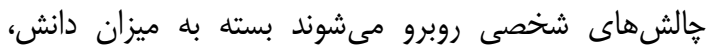
تجربه، ارتباطات و مهارتهاى اجتماعى كه دارند، واكنش

1. Aliabadi, V . P. Ataiee and R. Movahedi. 2016. The Effect of Strategic Thinking and Social C. on Recognition of Entrepreneurial Opportunities among Rural Youths (Case Study: Kangavar County). Journal of Research and Rural Planning, 5: 95-110 (In Persian).

2. Arasti, Z. and M. Gholami. 2010. Roots of entrepreneurs' failure in Iran. Journal of Entrepreneurship Development, 3: 173-196 (In Persian).

3. Bird, B. 1989. Entrepreneurial behavior. Glenview, IL: Scott, Foresman and Company, 31.

4. Eckhardt, J.T. and S.A. Shane. 2003. Opportunities and entrepreneurship. Journal of Management, 29: 333-349.

5. Gregoire, D.A., D.A. Shepherd and L. Schurer. 2009. Measuring opportunity recognition belifs: illustrating and validating an experimental approach. Organizational Research Methods, 13: 114- 145.

6. Khoshmaram, M. 2017. Designing a model for entrepreneurship opportunity recognition among agricultural entrepreneurs in Kermanshah Province. Ph.D. Thesis Razi University, Faculty of agriculture, Department of Agricultural Extension and Education, 206.

7. Khoshmaram, M., K. Zarafshani, A. Mirakzadeh and A. Alibaygi. 2017. Modeling Agricultural Entrepreneurial Opportunity Recognition in Kermanshah Province: Application of NVivo Software. Journal of Rural Research, 8: 388-403 (In Persian).

8. Krejcie, R.V. and D.W. Morgan. 1970. Determining sample size for research activities. Educational and Psychological Measurement, 30: 608-610.

9. Krueger, N.F. and D.V. Brazeal. 1994. Entrepreneurial potential and potential entrepreneurs. Entrepreneurship Theory and Practice, 91-104.

10. Omidvar, M., F. Amini and S. Hoseini. 2014. Identifying the roots of entrepreneurs' failure. Abstracts of Articles of the Second International Conference on Skills and Employment. Tehran, April, 5 pp (In Persian).

11. Ozgen, E. 2003. Entrepreneurial opportunity Recognition: Information flow, social and cognitive perspectives. Unpublished doctoral Dissertation, university of New York, 112.

12. Shapero, A. and L. Sokol. 1982. The social dimensions of entrepreneurship. In C. Kent, D. Sexton and K. Vesper (Eds.). Encyclopedia of entrepreneurship: Englewood Cliffs, NJ: Prentice Hall, 72-90.

13. Tang, J. 2010. How entrepreneurs discover opportunities in China: An institutional view, Asia Pacific Journal of Management, 27: 461-479. 
11 واكاوى نقش تلاطمهاى شخصى در تشخيص فرصتهاى كارآفرينانئ كشاورزى (مورد مطالعه: استان كرمانشاه) ..

14. Tang, J. 2016. Linking personal turbulence and creative behavior: The influence of scanning and search in the entrepreneurial process. Journal of Business Research, 69: 1167-1174.

15. Yaghobi, M. 2007. Treasures of the Elders of Iran and the World. Tehran: Attar Publishing, 57.

16. Yusefi, Z., N. Naderi, B. Rezaei and N. Shiri. 2015. Investigation and Prioritization of Expert's views of Agriculture Jihad Organization of Kermanshah on Factors Affecting the Development of Agricultural Entrepreneurship in Rural Areas, Journal of Entrepreneurial Strategies in Agriculture, 2(4): 53-61. 


\title{
Investigating the Role of Personal Turbulence in Entrepreneurial Opportunities Recognition in Agriculture Sector (The Case of Kermanshah Province)
}

\author{
Mozhgan Khoshmaram ${ }^{1}$, Kiomars Zarafshani ${ }^{2}$, Ali Asghar Mirakzadeh ${ }^{3}$ and \\ Amir Hossein Alibaygi ${ }^{2}$ \\ 1- Ph.D., Department of Agricultural Extension and Education, Faculty of Agriculture Razi University \\ (Corresponding author: Mkhoshmaram3@gmail.com) \\ 2 and 3- Associate Professor and Assistance Professor, Department of Agricultural Extension and Education, Faculty \\ of Agriculture, Razi University \\ Received: March 11,2018 Accepted: June 26, 2018
}

\begin{abstract}
Although a relatively neglected topic within the entrepreneurship and creativity literature, personal turbulence has been suggested to account for emergence of new ventures, intention to start a new business and opportunity recognition. On the basis of the predominant impact of personal turbulence on various crucial aspects of the entrepreneurial process, some scholars contend that personal turbulence will also offer a promising lens for gaining insights into entrepreneurs' creativity. In this regard, the purpose of this study was to investigating the role of personal turbulence in Entrepreneurial Opportunities Recognition in agricultural sector of Kermanshah province. The statistical population of this study consisted of all entrepreneurs in agricultural sector of Kermanshah province, that 102 of whom were selected by simple random sampling method. The instrument was a questionnaire that validity and reliability were confirmed by the panel of experts and Kuder-Richardson coefficients. The results of this study showed that entrepreneurial opportunities in agricultural sector was recognized correctly and successfully by entrepreneurs, because they investigated the feasibility, desirability and the degree of alignment between an opportunity's specific means of supply and a target market at the high level. In addition, findings showed that only $37.3 \%$ of the entrepreneurs in this study, before the start of entrepreneurial business and the recognition of agricultural entrepreneurship opportunities in their personal life were confronted with turbulence. The results of regression analysis indicated that the personal turbulence was able to explain $18 \%$ of variation variances in the entrepreneurship opportunities recognition in agricultural sector of Kermanshah province. The main implication of this study is to encourage policymakers, planners and managers to create a sense of self-esteem in villagers and farmers to take advantage of the huge potential of the agricultural sector.
\end{abstract}

Keywords: Agricultural entrepreneurship, Desirability of opportunity, Entrepreneurial actions, Feasibility of opportunity 